\title{
A review of malarial retinopathy in severe
}

\section{malaria}

\section{HL Sithole*}

University of South Africa, Research and Innovation Portfolio, Research Department, PO Box 392, UNISA, 0003

South Africa

<sithohl@unisa.ac.za>

Received 8 January 2011; revised version accepted 15 August 2011

\begin{abstract}
The ocular manifestations of severe malaria in patients with cerebral malaria $(\mathrm{CM})$ include retinal whitening, vessel discolouration, retinal haemorrhages and papilloedema. A large prospective study of Malawian children with CM found that the severity of retinal signs, including the number of retinal haemorrhages, was related to the outcome and length of coma in survivors of malaria. In a smaller number of Kenyan children with cerebral malaria, retinal haemorrhages were associated with deep coma and severe anaemia. A study on the effect of malarial retinopathy on vision found no detectable effect on visual acuity (VA) but where malaria is aggravated by failure to receive treatment this may possibly affect VA. The failure to receive treatment may be directly linked to the socio-economic status (SES) of those affected and this may occur in the KwaZulu-Natal, Mpumalanga and Limpopo prov-
\end{abstract}

inces of South Africa where malaria is endemic. This suggests the need for effective health education and health promotion amongst those affected by malaria especially in severely affected provinces of South Africa. Also, in view of the direct ocular consequences of severe malaria, optometrists should engage communities in health education and health promotion. This is particularly relevant because in some communities, a large majority of those suffering from malarial infections do not visit formal health facilities for treatment. In so doing, optometrists in South Africa will be contributing positively to the Millennium Development Goals which seek, amongst others, to reduce unwarranted sources of morbidity worldwide. ( $S$ Afr Optom 2011 70(3) 129-135)

Key words: Malaria, ocular changes in Malaria, malarial retinopathy, public health BOptom, MOptom

\section{Introduction}

Malaria is a mosquito-borne infectious disease caused by a eukaryotic protist of the genus plasmodium $^{1}$ that is widespread in tropical and subtropical regions, including parts of America, Asia, and Africa $^{2}$. Each year, there are more than 250 million cases of malaria worldwide, killing between one and three million people, the majority of whom are chil- dren in sub-saharan Africa ${ }^{2}$. Malaria is endemic in the low-altitude areas of the northern and eastern parts of South Africa with seasonal transmission ${ }^{3}$. These areas include parts of KwaZulu-Natal, Mpumalanga and Limpopo provinces ${ }^{3}$. Almost all South Africans lack acquired immunity, including residents of seasonal malaria transmissions areas, and are, therefore at risk of developing severe malaria ${ }^{4}$. Because ocular complications occur frequently in severe malaria ${ }^{5}$, it 
is therefore important for optometrists to know about such ocular complications associated with this disease, especially those providing eye care services in the malaria endemic regions of South Africa.

There are four types of malaria ${ }^{6}$, namely; plasmodium falciparum, plasmodium vivax, plasmodium ovale and plasmodium malariae. Most malaria infections and deaths are associated with plasmodium falciparum although the other types if untreated may also cause serious health problems ${ }^{7}$. Plasmodium falciparum is responsible for the retinopathy in severe malaria $^{8}$. The retina is embryologically part of the central nervous system with an analogous cellular structure and blood-tissue barrier ${ }^{9}$. This predisposes the microvasculature and the neurologic tissues of the retina to complications of systemic diseases including malaria. Plasmodium falciparum malaria, preponderantly in African children with cerebral malaria (CM) or severe malarial anaemia (SMA), causes the unique cluster of retinal signs ${ }^{7}$, collectively known as malarial retinopathy 9 . The severity of malarial retinopathy correlates with mortality and duration of coma in African children with $\mathrm{CM}$, suggesting that the retinopathy is related to the pathophysiology of the disease and is not an epiphenomenon 7 . Approximately two-thirds of such patients have retinopathy that can be seen using an indirect ophthalmoscope ${ }^{7}$, and the mortality in this group is more than double that of comatose children with no retinopathy ${ }^{10}$. Approximately one-half of patients with SMA have retinopathy, but is usually much milder than that seen in $\mathrm{CM}^{7}$. Retinopathy is rarely seen in patients with uncomplicated malaria ${ }^{11}$.

Malarial retinopathy consists of four main components, namely retinal whitening, vessel discolouration, retinal haemorrhages and papilloedema, see Table 1. The first two of these aforementioned abnormalities are unique to malaria ${ }^{7,11}$, and are not seen in other ocular or systemic conditions ${ }^{9}$. Cotton wool spots are also seen and are distinct from retinal whitening. Whilst papilloedema and retinal haemorrhages can be visualised with an ordinary direct ophthalmoscope, the distinctive retinal whitening and vessel abnormalities are found mostly in the peripheral retina and thus require indirect ophthalmoscopy ${ }^{9}$. See Figures 1 and 2 where retinal whitening near the fovea and the peripheral area is shown.
Table 1: Showing the components of malarial retinopathy

\begin{tabular}{|l|}
\hline Components of malarial retinopathy \\
\hline Retinal whitening \\
- $\quad$ Macular \\
Vessel changes \\
- Whitening (including orange vessels and tramlining) \\
- Capillary whitening \\
Retinal hemorrhages \\
Papilloedema \\
Cotton wool spots
\end{tabular}

Adapted from Beare et $a l^{9}$

\section{Components of malarial retinopathy}

\section{Retinal whitening}

Retinal whitening affecting the macula is termed macula whitening. When this feature occurs outside the macula, it is termed peripheral whitening. In some early reports, retinal whitening was referred to as retinal edema. Macular whitening is a patchy opacification of the retina centred on the fovea, but it spares the central fovea or foveola ${ }^{11}$ and frequently extends temporally between the vascular arcades as shown in Figure 1.

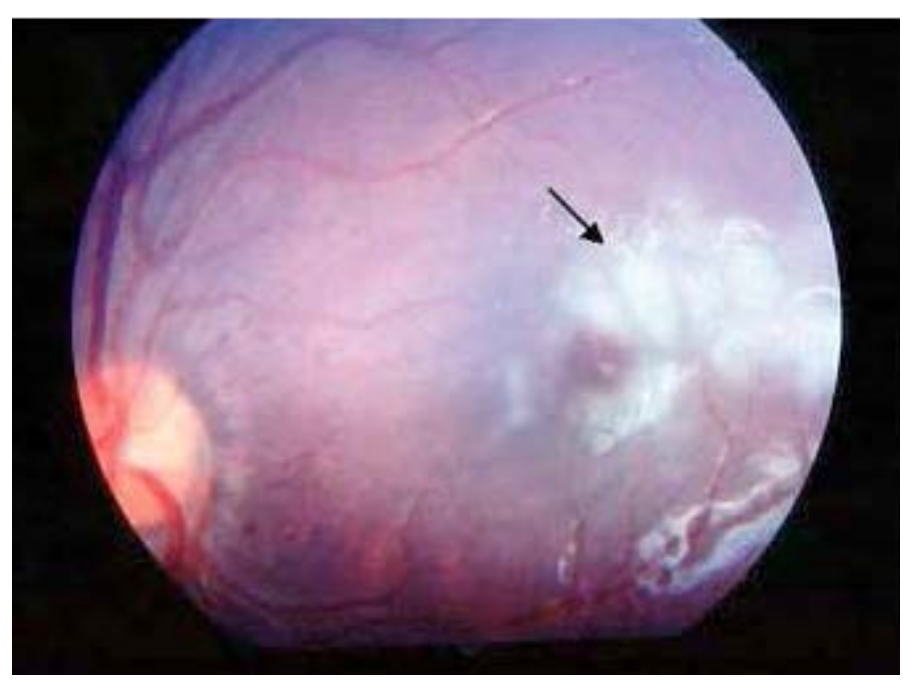

Figure 1: Severe macular whitening (solid arrow) completely surrounding the foveola of a Malawian child with cerebral malaria. (Adapted from Beare $e t a l^{7}$, and photograph courtesy of Dr Nicholas AV Beare) 
Figure 2 shows the peripheral whitening of the fundus which is similar in appearance to macular whitening but outside the temporal vascular arcades, or it can be a more mosaic pattern in the peripheral fundus. The appearance is distinct from cotton wool spots, which also occur, but less frequently. Patches of peripheral whitening associated with severe malaria are less well demarcated, less brightly white, and more widely distributed than cotton wool spots. Retinal whitening is similar in appearance to patchy ischemic retinal whitening, an uncommon finding in central retinal vein occlusion ${ }^{12}$, but has a different retinal distribution ${ }^{9}$.

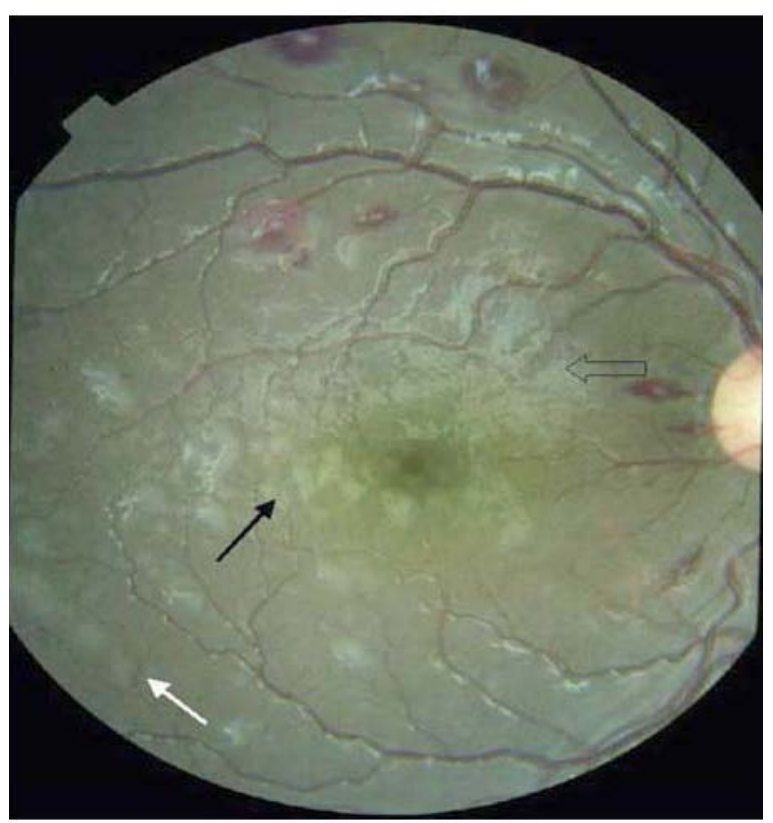

Figure 2: Macular whitening around inferior fovea and temporal macula (solid black arrow). Roth spots are temporal to the disc and on the superior macula. Peripheral whitening is outside the vascular arcades (solid white arrow). Open arrow indicates glare. (Adapted from Beare et $a l^{9}$, and photograph courtesy of Dr Nicholas AV Beare)

\section{Vessel discolouration}

Vascular changes such as discoloration of retinal vessels to orange or white, mainly in the peripheral fundus are shown in Figure 3. Either discrete sections of vessels, or peripheral vascular trees, can be involved. White or orange tramlining within larger vessels can occur (continous or interrupted), delineating an apparently narrowed blood column as shown in Figure 4. Capillary whitening refers to whitening of retinal capillaries and post-capillary venules such that they become prominent against the choroidal background. When viewed with a high magnifica- tion indirect lens (x 5.5), capillary whitening is more widely distributed in the fundus than has been previously recognised 9 .

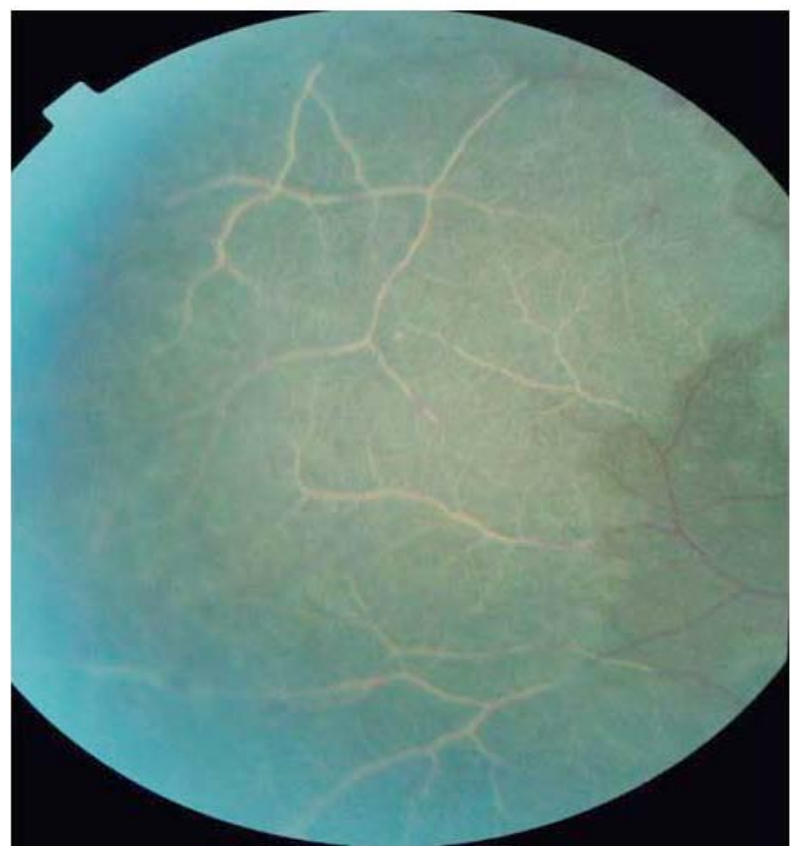

Figure 3: White retinal vessels in an area of confluent peripheral retinal whitening. (Adapted from Beare et $a l^{9}$ and photograph courtesy of Dr Nicholas AV Beare)

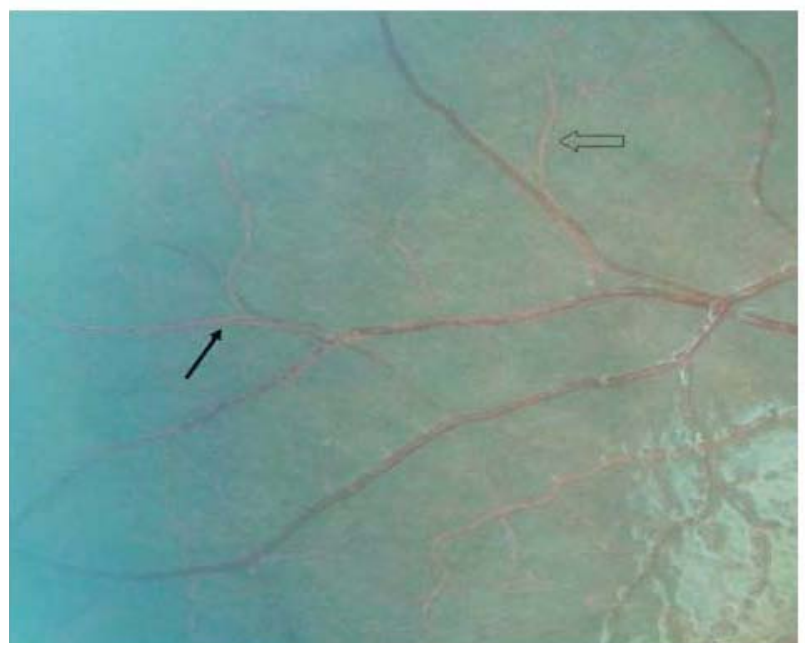

Figure 4: Vessel changes in same child as in Figure 1, including examples of tramlining (solid arrow) and orange vessel (open arrow). (Adapted from Beare $e t a l^{9}$ and photograph courtesy of Dr Nicholas AV Beare)

\section{Haemorrhages}

Retinal haemorrhages are predominantly whitecentred, intra-retinal, blot haemorrhages similar to Roth spots (see Figure 2). In severe cases, these can be extremely numerous ( $>120$ in each eye) and overlapping as shown in Figure 5. Flame and large blot haemorrhages also occur frequently. Occasionally, 
haemorrhages can extend into the pre-retinal space ${ }^{13}$.

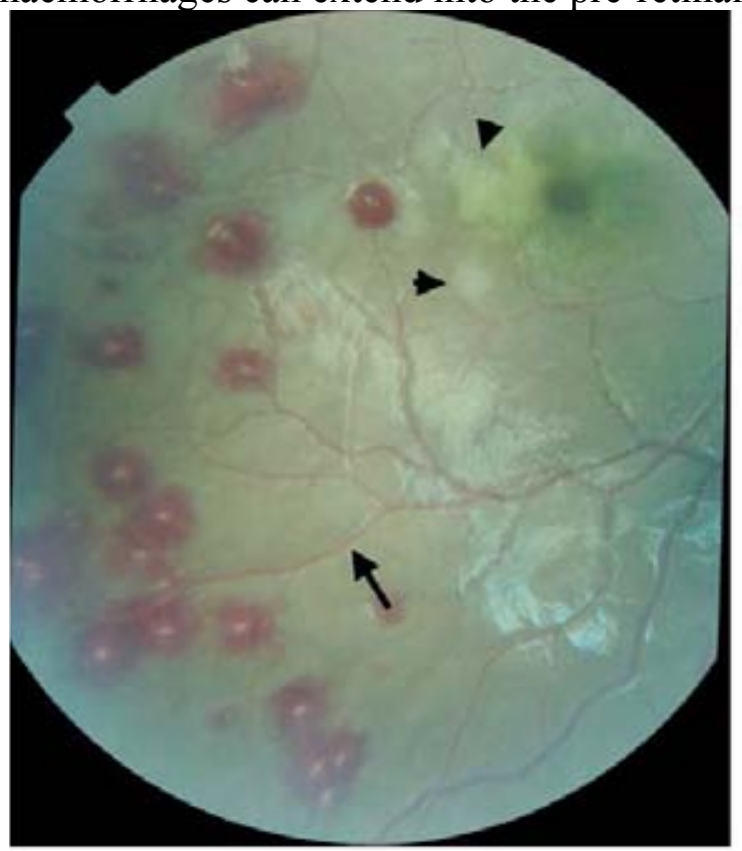

Figure 5: Fundus photograph displaying malarial retinopathy consisting of multiple Roth spots, macular whitening (arrowheads) and orange discoloration of vessels (arrow). (Adapted from Beare et $a l^{9}$ and photograph courtesy of Dr Nicholas AV Beare)

\section{Papilloedema}

Papilloedema is not specific to malaria and can occur in many other conditions that cause coma. Disc oedema accompanies retinal features of CM in a proportion of cases and independently increases the risk of fatal outcome ${ }^{7}, 14$. When papilloedema is present without retinal whitening, vessels changes, or whitecentred haemorrhages, the examiner should consider causes of raised intracranial pressure ${ }^{9}$.

\section{Pathophysiological mechanisms of malarial retin- opathy}

There is good evidence that the pathological mechanisms which produce malarial retinopathy in severe malaria are the same as those which cause coma in $\mathrm{CM}^{13}$. As well as correlating with disease severity, the retinal changes have histological correlates that match histological findings in the brain. Sequestration of infected erythrocytes occurs in the retinal microvasculature in the same fashion as the cerebral microvasculature and is thought to cause the retinal vessel discolouration ${ }^{15}$. The number of retinal haemorrhages correlates with the density of brain haemorrhages and, like cerebral haemorrhages, they have fibrin at their centre $^{16}$. This is not surprising as the retina is embryologically derived from the same nueroectoderm as the brain and has the same type of vasculature within a structure of neurons and glial cells ${ }^{13}$.

Reduced blood flow is the pathological sequel of microcirculatory obstruction ${ }^{13}$. This is suggested by the histological appearance of cytoadherent erythrocytes containing mature forms of the parasite sequestrated in the microvasculature, narrowing vessel lumens ${ }^{13}$. The physical obstruction by these rigid cytoadherent parasitized erythrocytes is compounded by the reduced red cell deformability and adhesive forces between infected erythrocytes (autoagglutination) and between infected and uninfected erythrocytes (rosetting $)^{17}$. Impaired perfusion has been demonstrated in vivo by flourescein angiography of the retina in 28 to 34 children with $\mathrm{CM}$ in a study in Malawi ${ }^{18}$. The majority of these children had vessel obstruction at the capillary level and associated small zones of nonperfusion ${ }^{13}$. The areas of non-perfusion matched areas of retinal whitening seen in malarial retinopathy, strongly supporting the hypothesis that microcirculatory obstruction and resulting hypoxia lead to retinal whitening ${ }^{13}$. Approximately one-quarter of these patients also had larger occluded vessels with larger associated zones of retinal perfusion ${ }^{13}$.

If these patterns of non-perfusion, with extensive heterogeneity of microvascular obstruction, are mirrored in the brain then a model is suggested whereby there are multiple small zones or reduced perfusion resulting in gradients of tissue hypoxia ${ }^{13}$. These may be partially or fully compensated by adjacent vasodilation and hyperperfusion. These multiple lacunae of hypoxia or ischaemia would be compatible with the absence of gross neurological deficits in most patients on recovery and also in keeping with the subtle neurocognitive deficits that are evident in African children years after an episode of $\mathrm{CM}^{19-21}$.

The retina provides a unique opportunity to observe the central nervous system vasculature directly and therefore to study cerebral vasculature directly ${ }^{13}$. The only other technique that currently allows detailed, direct, relatively non-invasive observation of microcirculatory flow is orthogonal polarising spectroscopy (OPS) ${ }^{13}$. OPS has been used to demonstrate reduced microcirculatory blood flow in the rectal mucosa in adult patients with $\mathrm{CM}^{22}$, although this technique has yet to be used in children ${ }^{13}$. The severity 
of flow obstruction in this study correlated with the severity of the disease ${ }^{13}$.

The major hypothesis to explain the pathophysiology of CM is the local or systemic release of inflammatory mediators such as cytokines and nitric oxide ${ }^{23}$. The evidence from the eye goes against this hypothesis $^{13}$. Retinal whitening is seen more in watershed zones and not along vessels, as would be expected if a causal substance was 'leaking' from the blood into the surrounding tissues, whereas the former points more towards a perfusion deficit ${ }^{13}$.

Studies of the integrity of the blood-brain barrier (BBB) in CM have relied on global measures of cerebral spinal fluid composition or on autopsy specimens in those that have died ${ }^{13}$. These have been equivocal, showing minor increases in BBB permeability, and have not demonstrated a breakdown in the BBB to a degree that would account for the degree of brain swelling ${ }^{13}$. Magnetic resonance imaging suggests the brain is congested with blood, and not full of water $^{24}$. The retina has a blood-retinal barrier (BRB) that is structurally and functionally the same as the brain and its integrity is tested by flourescein angiography ${ }^{13}$. Although the BRB breakdown occurred in $44 \%$ of children with CM, it only affected limited portions of a few vessels and to a minor degree ${ }^{18}$. It was seen adjacent to ischemic zones or in areas that had not been perfused but later recovered ${ }^{13}$. It did not occur in discoloured vessels or vessels narrowed by sequestration ${ }^{13}$. This suggests that breakdown of the blood-tissue barrier is a non-specific response to severe disease, possibly as a result of local hypoxia compounded by endothelial dysfunction ${ }^{13}$.

\section{Detection of malarial retinopathy}

Papilloedema and retinal haemorrhages had been previously reported by investigators using direct ophthlmoscopy ${ }^{25-27}$, but the components specific to malarial retinopathy are best seen by indirect ophthalmoscopy through dilated pupils ${ }^{9}$. Although retinal haemorrhages, pappilloedema, and macular whitening are detectable with direct ophthalmoscopy, studies recognizing a high incidence of malarial retinopathy have used indirect ophthalmoscopy ${ }^{7}, 28,29$. The wider field of view afforded by the indirect ophthalmoscope allows visualization of the peripheral retina where the unique vascular changes are mostly situated, beyond the view of the direct ophthalmoscope ${ }^{\text {. }}$

In children, severe malaria presents as three syndromes that commonly overlap: CM, SMA and respiratory distress or metabolic acidosis. In these conditions, malarial retinopathy is more likely to be detected. The most notable signs, as indicated earlier, are the retinal whitening and vessel changes that are not seen in any other ocular or systemic condition. Malarial retinopathy is also seen in other manifestations of severe malaria without coma, but the retinopathy is generally less severe, with fewer of the component changes ${ }^{7}$. Occasional retinal haemorrhages can be seen in children with non-severe malaria ${ }^{30}$. This may suggests the need for optometric evaluation of all patients diagnosed with malaria.

In adults, the clinical features of severe malaria are different from those in children, with multi-system involvement including renal failure, hepatic dysfunction, pulmonary edema and disseminated intravascular coagulation being common ${ }^{9}$. In a study done on Thai and Indian adults $25,31,32$ with CM, it was found that retinal haemorrhages were less frequent than in children. Retinal edema and exudates have been described as infrequent findings, but these may presume etiologies that are unproven, and it is not clear whether they refer to retinal whitening seen in children ${ }^{9}$. However, macular retinal whitening has been observed in two Malawian adults with $\mathrm{CM}$ in a prospective study of patients admitted with fever ${ }^{33}$. It is important to note that malarial retinopathy does not seem to be a prominent feature in adults as found in children, but care should always be taken when examining adults with history of malaria infections not to miss the retinopathy.

\section{Prognostic significance and outcome}

Malarial retinopathy in severe malaria has been well described in African children, and its prognostic and diagnostic value is established in these patients ${ }^{7}$. A large prospective study of Malawian children with $\mathrm{CM}$ found that the severity of retinal signs, including the number of retinal haemorrhages, was related to the outcome and length of coma in survivors of malaria ${ }^{7}$. This concurred with earlier studies that found that ocular fundus signs were associated with an increased risk of death ${ }^{14,34}$. In a smaller number of Kenyan children with cerebral malaria, retinal haem- 
orrhages were associated with deep coma and severe anaemia ${ }^{29}$. In children in Mali with malaria, retinopathy was related to severity, but this study is difficult to compare with other studies in African children because it does not state the method of ophthalmoscopy used and uses a more inclusive definition of $\mathrm{CM}^{30}$.

Malarial retinopathy resolves some time after the resolution of coma in $\mathrm{CM}$ and with no persisting retinal abnormalities ${ }^{35}$. A study on its effect on vision found no detectable effect of retinopathy on visual acuity (VA) in the first month of discharge ${ }^{35}$. However, this study made use of relatively crude measures of VA in a young age group in whom accurate assessment of vision is to a certain extent difficult ${ }^{9}$. Also, it is possible that VA may be somewhat affected in cases where patients are not treated for the retinopathy.

\section{Challenges for public health with malaria}

Malaria is commonly recognized as a disease of poverty ${ }^{36-38}$. According to Worral et $a^{39}$, the uptake of a variety of preventive measures against diseases is consistent with the socio-economic status (SES) of those affected. This means that the higher the SES the more the preventive measures taken but, the lesser the SES the less the preventive measures taken. Also, under-diagnosis of malarial illness in an endemic area is more commonly as a result of failure on the part of the patient to reach a health facility than the result of clinical assessment when at a health facility ${ }^{1}$. In the light of these challenges, it is possible that some patients living in the low-altitude areas of South Africa where malaria is endemic ${ }^{39-43}$ are not visiting health facilities for treatment as a result of their SES. Although this may be the case, there is a need for effective awareness campaigns by health care personnel such as optometrists since malaria is directly linked to ocular complications.

\section{Conclusion}

Although there is no record of statistics on the prevalence of malarial retinopathy in South Africa, it is possible that patients with severe malaria are also affected by its ocular consequences. Therefore, it is recommended that a study on the prevalence of malarial retinopathy among patients diagnosed with severe malaria be conducted in South Africa. This would certainly reveal the extent to which this important problem may be affecting patients with malaria who are living in areas where ophthalmological and optometric services are inadequate, especially in the three provinces where malaria is endemic. Also, in view of the direct ocular consequences of severe malaria, it may be important for optometrists to engage communities in health education and health promotion because in some communities, a large majority of those suffering from malarial infections do not visit formal health facilities for treatment. In so doing, optometrists in South Africa will be contributing positively to the Millennium Development Goals which seek, amongst others, to reduce unwarranted sources of morbidity worldwide.

\section{References}

1. Koram KA, Molyneux ME. When is "Malaria" malaria? The different burdens of malaria infection, malaria disease, and malaria-like illnesses. Am J Trop Med Hyg 200777 1-5.

2. Snow RW, Guerra CA, Noor AM, Myint HY, Hay. The global distribution of clinical episodes of Plasmodium falciparum malaria. Nature 2005434 214-217.

3. Gerristen AAM, Kruger P, Van der Loeff MFS, Grobusch MP. Malaria incidence in Limpopo Province, South Africa, 1998-2007. Malaria Journal 20087 162-169.

4. Gross J, Gross FJ, Friedman AH. Systemic infections and inflammatory diseases. Tasman W, Jaeger EA, eds. Duane's Clinical Ophthalmology. Vol. 5 Revised edition. Philadelphia: JB Lippincott 199133 1-45.

5. Blumberg L, Frean J. Malaria control in South Africa-challenges and successes. SAMJ 2007 97 1193-1197.

6. 6. Marx A, Pewsner D, Egger M, Nuesch R, Bucher HC, Genton B, Hatz C, Juni P. Meta-Analysis: Accuracy of rapid tests for malaria in travelers returning from endemic areas. Ann Int Med 2005142 836-846.

7. Beare NA, Southern C, Chalira C, Taylor TE. Prognostic significance and course of retinopathy in children with severe malaria. Arch Ophthalmol 2004122 1141-1147.

8. White VA, Lewallen S, Beare NAV, Molyneux ME, Taylor TE. Retinal pathology of paediatric malaria in Malawi. PLoS ONE 20094 e4317.

9. Beare NAV, Taylor TE, Harding SP, Lewallen S, Molyneux ME. Malarial retinopathy: a newly established diagnostic sign in severe malaria. Am J Trop Med Hyg 200675 790797.

10. Lewallen S, Brozman RN, Beare NA, Harding SP, Molyneux ME, Taylor TE. Using malarial retinopathy to improve the classification of children with celebral malaria. Trans $R$ Soc Trop Med Hyg 2008102 1089-1094.

11. Lewallen S, Harding SP, Ajewole J, Schulenberg WE, Molyneux ME, Marsh K, Usen S, White NJ, Taylor TE. A review 
of the spectrum of clinical ocular fundus findings in P. falciparum malaria in African children with a proposed classification and grading system. Trans $R$ Soc Trop Med Hyg 199993 619-622.

12. Browning DJ. Patchy ischemic retinal whitening. Arch Ophthalmol 2004111 606-607.

13. Maude RJ, Dondorp AM, Sayeed AA, Day NPJ, White NJ, Beare NAV. The eye in cerebral malaria: what can it teach us? Trans R Soc Trop Med Hyg 2009103 661-664.

14. Lewallen S, Bakker H, Taylor TE, Wills BA, Courtright $\mathrm{P}$, Molyneux ME. Retinal findings predictive of outcome in cerebral malaria. Trans R Soc Trop Med Hyg 199690 144-146.

15. Lewallen S, White VA, Whitten RO, Gardiner J, Hoar B, Lindley $\mathrm{J}$, et al. Clinical-histopathological correlation of the abnormal retinal vessels in cerebral malaria. Arch Ophthalmol 2000118 924-928.

16. White VA, Lewallen S, Beare N, Kayira K, Carr RA, Taylor TE. Correlation of retinal haemorrhages with brain haemorrhages in children dying of cerebral malaria in Malawi. Trans R Soc Trop Med Hyg 200195 618-621.

17. Dondorp AM, Kager PA, Vreeken J, White NJ. Abnormal blood flow and red cell deformability in severe falciparum malaria. Parasitol Today 200016 228-232.

18. 18. Beare NAV, Harding SP, Taylor TE, Lewallen S, Molyneux ME. Perfusion abnormalities in children with cerebral malaria and malarial retinopathy. J Infect Dis Epub 2009 199 263-271.

19. Boivin MJ. Effects of early cerebral malaria on cognitive ability in Senegalese children. J Dev Behav Pediatr 2002 23 353-364.

20. Carter JA, Ross AJ, Neville BG, Obiero E, Katana K, Mung'ala-Odero V, Lees JA, Newton CR. Development impairments following severe falciparum malaria in children. Trop Med Int Health 200510 3-10.

21. Kihara M, Carter JA, Newton CR. The effect of Plasmodium falciparum on cognition: a systemic review. Trop Med Int Health 200611 386-397.

22. Dondorp AM, Pongpontran E, White NJ. Reduced microcirculatory flow in severe falciparum malaria: pathophysiology and electromicroscopic pathology. Acta Trop 2004 89 309-317.

23. Clark IA, Schofield L. Pathogenesis of malaria. Parasitol Today 200016 451-454.

24. Looareesuwan S, Wilairatana P, Krishna S, Kendall B, Vannaphan S, Viravan C, White NJ. Magnetic resonance imaging of the brain in patients with cerebral malaria. Clin Infect Dis 199521 300-309.

25. Looareesuwan S, Warrell DA, White NJ, Chanthavanich P, Warell MJ, Chantaratherakitti S, Changswek S, Chongmankongcheep L, Kanchanaranya C. Retinal haemorrhage, a common sign of prognostic significance in cerebral malaria. Am J Trop Med Hyg 198332 911-915.

26. Newton CR, Winstanley PA, Marsh K. Retinal haemorrhages in falciparum malaria. Arch Dis Child 199166753.

27. 27. Haslett P. Retinal haemorrhages in Zambian children with cerebral malaria. J Trop Peadiatr 199137 86-87.
28. Lewallen S, Bakker H, Taylor, TE, Wills BA, Courtright $\mathrm{P}$, Molyneux ME. Retinal haemorrhage in vivax malaria. Trans R Soc Trop Med Hyg 199690 144-146.

29. 29. Hero M, Harding SP, Riva CE, Winstanley PA, Peshu N, Marsh K. Photographic and angiographic characterization of the retina of Kenyan children with severe malaria. Arch Ophthalmol 1997115 997-1003.

30. Schemann JF, Doumbo O, Malvy D, Traore L, Kone A, Sidibe T, Keita M. Ocular lesions associated with malaria in children in Mali. Am J Trop Med Hyg 200267 61-63.

31. Kochar DK, Shubhakaran, Kumawat BL, Thanvi I, Joshi A, Vyas SP. Ophthalmoscopic abnormalities in adults with falciparum malaria. QJM 199891 845-852.

32. 32. Kochar DK. Shubhakaran, Kumawat BL, Vyas SP. Prognostic significance of eye changes in cerebral malaria. J Assoc Physicians India 200048 473-477.

33. Beare NA, Lewis DK, Kublin JG, Harding SP, Zijlstra EE, Molyneux ME. Retinal changes in adults with cerebral malaria. Ann Trop Med Parasitol 200397 313-315.

34. Lewallen S, Taylor TE, Molyneux ME, Wills BA, Courtright $\mathrm{P}$, Ocular fundus findings in Malawian children with cerebral malaria. Arch Ophthalmol 1993100 857-861.

35. Beare NAV, Southern C, Kayira K, Taylor TE, Harding SP. Visual outcomes in children in Malawi following retinopathy of severe malaria. Br J Ophthalmol 200488 321-324.

36. Gallup JL, Sachs JD. The economic burden of malaria. Am J Trop Med Hyg 200164 85-96.

37. Sachs J, Malaney P. The economic and social burden of malaria. Nature 2002415 680-685.

38. World Health Organization /UNICEF. The Africa Malaria Report. World Health Organization/UNICEF, Geneva, 2003.

39. Worrall E, Basu S, Hanson K. Is malaria a disease of poverty? A review of the literature. Trop Med Int Health 2005 10 1047-1059.

40. Greenwood BM, Greenwood AM, Bradley AK, Tulloch S, Hayes R, Oldfied FS. Deaths in infancy and early childhood in a well-vaccinated, rural, West African population. Ann Trop Peadiatr 1987 91-99.

41. Craig MH, Snow RW, Le Sueur D. A climate-based distribution model of malaria transmission Africa. Parasitol Today 199915 105-111.

42. Craig MH, Kleinschmidt I, Le Sueur D, Sharp BL. Exploring 30 years of malaria case data in KwaZulu-Natal, South Africa: Part II. The impact of non-climatic factors. Trop Med Int Health 20049 1258-1266.

43. Coleman M, Coleman M, Mabaso MLH, Mabuza AM, Kok G, Coetzee M, Durrheim DN. Household and microeconomic factors associated with malaria in Mpumalanga, South Africa. Trans R Soc Trop Med Hyg 2010104 143147. 